Original article

\title{
Low birth weight among tribal in India: Evidence from National Family Health Survey-4
}

\author{
Nutan Kumari ${ }^{\mathrm{a}}$, Kisan Algur ${ }^{\mathrm{b}}$, Praveen Kailash Chokhandre ${ }^{\mathrm{c}}$, Pradeep S. Salve ${ }^{\mathrm{d}, *}$ \\ ${ }^{a}$ Department of Fertility Studies, International Institute for Population Science, Deonar, Mumbai, 400088, India \\ ${ }^{\mathrm{b}}$ International Institute for Population Sciences, Mumbai, 400 088, India \\ ${ }^{\mathrm{c}}$ International Institute for Population Sciences, Govandi Station Road, Deonar, Mumbai, 400088, India \\ ${ }^{\mathrm{d}}$ Population Research Centre, JSS Institute of Economic Research, Kausalya Building, Vidhyagiri, Dharwad, 580 004, Karnataka, India
}

A R T I C L E IN F O

\section{Keywords:}

Low birth weight

Scheduled tribe

NFHS-4

India

\begin{abstract}
A B S T R A C T
Aim: The study aims to investigate the Low Birth Weight (LBW) of newborn infants among the tribal population in India.

Methods and Materials: Study analyses 1,93,345 tribal children aged 0-5 years from the fourth round of the National Family Health Survey data (NFHS-4, 2015-16). Logistics regression has been performed to investigate the correlates of low birth weight.

Results: Results show that every fifth newborn child among tribal in 165 districts is LBW and total of 232 districts have proportionately higher LBW than the national average (18.2\%). Newborns belonging to Scheduled Tribes in Madhya Pradesh (30 districts), Maharashtra (19 districts), Rajasthan (19 districts), Odisha (19 districts), Gujarat (16 districts), Bihar (12 districts), Karnataka (10 districts), West Bengal (9 districts) and Andhra Pradesh (5 districts) - have higher proportion of low birth weight than the national average. Univariate Global Moran's I index shows that $21 \%$ of districts have positive auto correlation for the prevalence of LBW among tribals. Mother's age at birth, mother's education, ANC visits and wealth index are important in determining the LBW of a newborn.

Conclusion: The prevalence of LBW is higher among tribal population. Mother's education, wealth index, ANC visits, Mother's age at birth are key determinants that need to be addressed to reduce prevalence of LBW among the tribal population. The government needs to focus on marginalized communities with target based intervention and policies.
\end{abstract}

\section{Introduction}

Newborn infants with weight less than $2500 \mathrm{~g}$ are identified as Low Birth Weight (LBW) infants by the World Health Organization. ${ }^{1}$ It has a significant association with perinatal survival, infant morbidity, mortality, and lifetime risk of developmental disabilities and diseases among infants. ${ }^{2}$ Reducing the prevalence of LBW by $30 \%$ is a public health priority and global health commitment. ${ }^{3}$ The estimates indicate that one in seven live births (20.5 million infants) globally fell in the low birth weight category in 2015, and almost half of them are from South Asia. Moreover, around $40 \%$ of LBW infants are from India., More than one-fourth (27\%) of newborns in India are LBW, which subsequently increases their death rate during the first year of life. ${ }^{6}$ The communities with poor socioeconomic conditions and residing in hard to reach areas have a higher number of LBW infants, for instance, about
$18 \%$ infants born in the tribal community are LBW. ${ }^{7,8}$

The problem of LBW is multidimensional. ${ }^{9}$ Previous studies highlighted that the socioeconomic status, place of residence, nutritional status of the mother, multiple pregnancies and gestation period determined the outcome of delivery including LBW, higher risk of death, morbidity and disability. ${ }^{1,7,10,11}$ Less access to antenatal care visits also affects the outcome of pregnancy in developing countries because during pregnancy women are given counselling for nutritional intake if they are found to be anaemic. ${ }^{12}$ In particular, expecting mothers from the tribal population are one of the most deprived social groups who live in remote geographical areas. According to the 2011 census, the tribal population in India was 104 million, constituting $8.6 \%$ of the country's population, up from $8.2 \%$ in 2001 census. While $40.6 \%$ tribals were below the poverty line, the proportion among the rest was $20.5 \%$. Key health indicators among the tribal communities still remain very

\footnotetext{
* Corresponding author.

E-mail addresses: nutan.dudi@gmail.com (N. Kumari), kdalgur90@gmail.com (K. Algur), praveenchokhandre@gmail.com (P.K. Chokhandre), pradeep8889@gmail.com (P.S. Salve).
} 
poor. Literature suggests that the prevalence of the LBW infants is found to be high among the tribal-dominated states in India. ${ }^{13-15}$ With this background, the present study aims to investigate the low birth weight among the tribal community in India at the district level. The findings of the study will be helpful to pinpoint the districts having higher prevalence of LBW among tribal children thereby informing policy interventions.

\section{Methods and materials}

\subsection{Data source}

The present study has used the data from the fourth round of the National Family Health Survey - 2015-16 (NFHS-4). The NFHS fourthround collected data between 2015 and 2016 from 29 states, 7 union territories, and 640 districts. The survey provides self-reported information on maternity history, fertility preference, socioeconomic and demographic characteristics. NFHS-4 adopted a multistage stratified random sampling method for data collection. Details of the sample size, design, and sample weights can be obtained from the NFHS-4 report. ${ }^{16}$ It provides information for children aged 0-5 years. Total of 1,93,345 children age $0-5$ years were covered in the survey and for the present study, we have analysed 35,029 tribal children in 20 selected states where tribal population is dominant. These include; Madhya Pradesh, Maharashtra, Orissa, Gujrat, Rajsthan, Jharkhand, Chhattisgarh, Andhra Pradesh, West Bengal, and Karnataka with a higher number of Scheduled Tribes. These states account for $83.2 \%$ of the total Scheduled Tribe population of the country. Assam, Meghalaya, Nagaland, Jammu \& Kashmir, Tripura, Mizoram, Bihar, Manipur, Arunachal Pradesh, and Tamil Nadu, accounting for another $15.3 \%$ of the total Scheduled Tribe population. ${ }^{17}$

\subsection{Dependent and explanatory variables}

We identified that there is a strong association between the birth weight of the infant and the mother's age, education, parity, and income of the household and the total number of antenatal visits made. ${ }^{18,19}$ However, mothers in under privileged socioeconomic settings often have LBW infants. In those settings, the child's low birth weight stems mainly from the mother's poor health and nutrition conditions for an extended duration. Birth weight is an important indicator when assessing a child's health for early exposure to childhood morbidity and mortality. Children who have weight less than $2.5 \mathrm{~kg}$ at birth are considered to have a higher-than-average risk of early childhood death. ${ }^{1,16}$

\subsection{Dependent variable}

In the NFHS-44, birth weight was recorded from either a written record or the mother's report. The mother's estimation of the infant's size at birth was also obtained because the birth weight is unknown for many infants. Each child's mother provided the birth-weight data either from a written record or by a recall. In the analysis, each child was coded as ' 1 ' for having LBW if the birth weight has been less than $2500 \mathrm{~g}$; otherwise was coded as ' 0 '.

\subsection{Explanatory variable}

Explanatory variables are identified as the possible covariates that have an association with an LBW child socioeconomic characteristics such as sex of child (female and male), birth order (first, second, third and fourth + ), place of residence (urban and rural), religion (hindu, muslim and others), mother's age at birth (below 18 and equal or more than 18), mother's education (no education, primary, secondary and higher), ANC visits (no ANC visit, less than 4 and equal or more than 4 visits) and wealth index (poorest, poorer, middle, richer and richest).

\subsection{Statistical analysis}

The association of these variables with LBW was investigated using the bivariate statistical analysis that has been done by using the statistical software package SPSS version 20. The QGIS 3.12.0 software package is used for geographical analyses.

Univariate Local Moran-I method is used to show the spatial autocorrelation effects among a different neighbouring district in India. And also, cluster analysis at the district level with the help of Geo-Da geographical analytical software. The cluster analysis and spatial autocorrelation carried out between different tribal-dominated districts of India for LBW. Local Moran statistic classified by type of spatial correlation: high-high association (higher LBW value shares boundary with high LBW value), low-low association (low LBW value shares boundary with low LBW value), low-high association (low LBW value shares boundary with high LBW value), and high-low association (high LBW value shares boundary with low LBW value). The high-high and lowlow locations suggest clustering of similar values, whereas the high-low and low-high locations indicate spatial outliers. The Moran's I statistic reflects the spatial pattern of values indicating clustered, dispersed, or random. Moran's index value near +1.0 indicates clustering, while an index value near -1.0 indicates dispersion and an index value of 0 indicates random.

\section{Results}

Results revealed that every fifth newborn in 165 districts of India have LBW and a total of 232 districts have higher percent of LBW newborns than the national average (18.2\%) among the tribal population in India. The percentage distribution of LBW by different social groups presented in Fig. 1 shows that the infants from Schedule Tribe have a higher prevalence of LBW as compared to other social groups in India Fig. 1). Scheduled Tribe infants born in Madhya Pradesh (30 districts), Maharashtra (19 districts), Rajasthan (19 districts), Odisha (19 districts), Gujarat (16 districts), Bihar (12 districts), Karnataka (10 districts), West Bengal (9 districts) and Andhra Pradesh (5 districts)

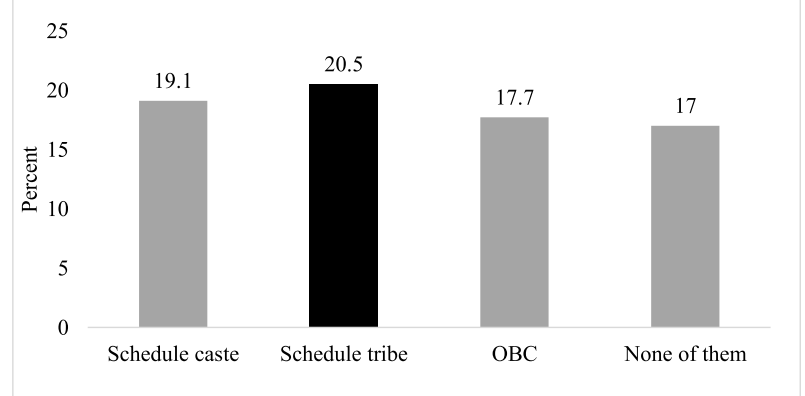

Fig. 1. Prevalence of the low birth weight $(<2.5 \mathrm{Kg})$ by social groups in India Sources: National family health survey (NFHS-4, 2015-16). 


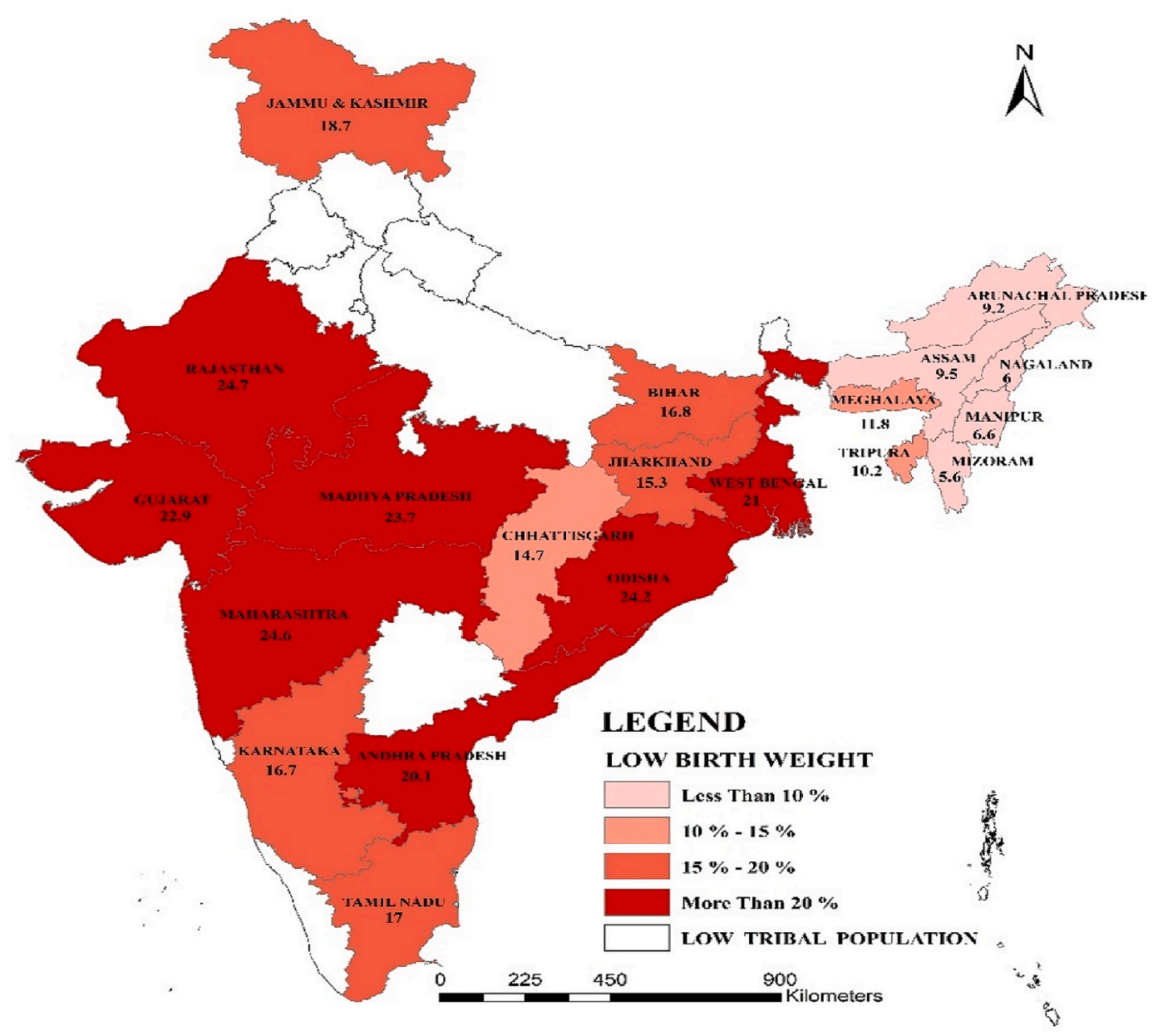

Fig. 2. Prevalence of LBW $(<2.5 \mathrm{~kg})$ in the tribal dominated states in India.

have higher proportion of low birth weight than the national average of India (Fig. 2). The district-level analysis revealed that infants in Jhabua (41\%), Ashoknagar (44\%), Tikamgarh (46\%), Mandsaurm (47\%), Gwalior (49\%) of Madhya Pradesh have higher LBW newborns. Similarly, districts like Buxar (46\%), Madhubani (49\%), Begusarai (53\%) and Saharsa (100\%) of Bihar; Bharatour (44\%), Gagaur (46\%), Jodhpur (50\%) and Dhaulpur (56\%) from Rajasthan have higher LBW newborns than the national average. At the same time, Osmanabad (40\%) and Hingoli (41\%) districts of Maharashtra; Udupi (47\%) of Karnataka; Bhadrak (51\%) of Odisha; Namakkal $(57 \%)$ of Tamil Nadu; Uttar Dinajpur and Murshidabad (100\%) of West Bengal have newborn with low weight compared to the national average (Fig. 3a-b).

In (Fig. 4a), Univariate Global Moran's I index shows that $21 \%$ of districts have positive autocorrelation for the prevalence of LBW among tribals. Moran's I index Local Indication of Spatial Association (LISA) map in (Fig. 4b) shows that around 26 high-high districts and 56 lowlow districts are positively correlated LBW among tribals and on the other hand 12 districts low to high, 6 districts high to low these two categories showing negative autocorrelation or outliers. (Fig. 4c) indicating the LISA significance map of LBW among tribal showing that 338 districts of India had no significant neighbourhood association, whereas 72 districts were associated with 95\% CI, 22 districts were associated with 99\% and 6 districts were associated with $99.9 \%$ CI. However, the mother's age at birth shows that less than 18 age years has high low birth children weight as compared to mother's age equal or more than 18 years. Mother's education also plays an important role; a mother with no education has lower birth weight child as compared to higher education. ANC visit shows that, those women who have not visited any ANC found to have children with low birth weight compared to women visiting 4 or more times. There was a gradient in the prevalence of low birth weight across categories of household wealth, for instance, the highest prevalence of LBW was found among children belonged poorest wealth index as compare to richest wealth index (Table 1).

Results from the multivariate logistic regression shows that male children (OR: 0.88 ; 95\% CI: 0.82-0.94) significantly likely to have low LBW among tribals than the female. The multiple pregnancies (OR: 0.75 ; 95\% CI: 0.67-0.84) and mother's residing in the rural area (OR: 0.29; $95 \%$ CI: 0.84-1.05) show similar results for the LBW. Likewise, mother's age at birth equal or more than 18 years (OR: 0.49 ; $95 \% \mathrm{CI}$ : $0.82-1.00$ ), Higher education (OR: 0.65 ; 95\% CI: $0.53-0.79$ ) and belonging to Richest wealth index (OR: $0.67 ; 95 \%$ CI: $0.54-0.81$ ) are significantly less likely to have LBW children among the tribal population (Table 2). 
(a)

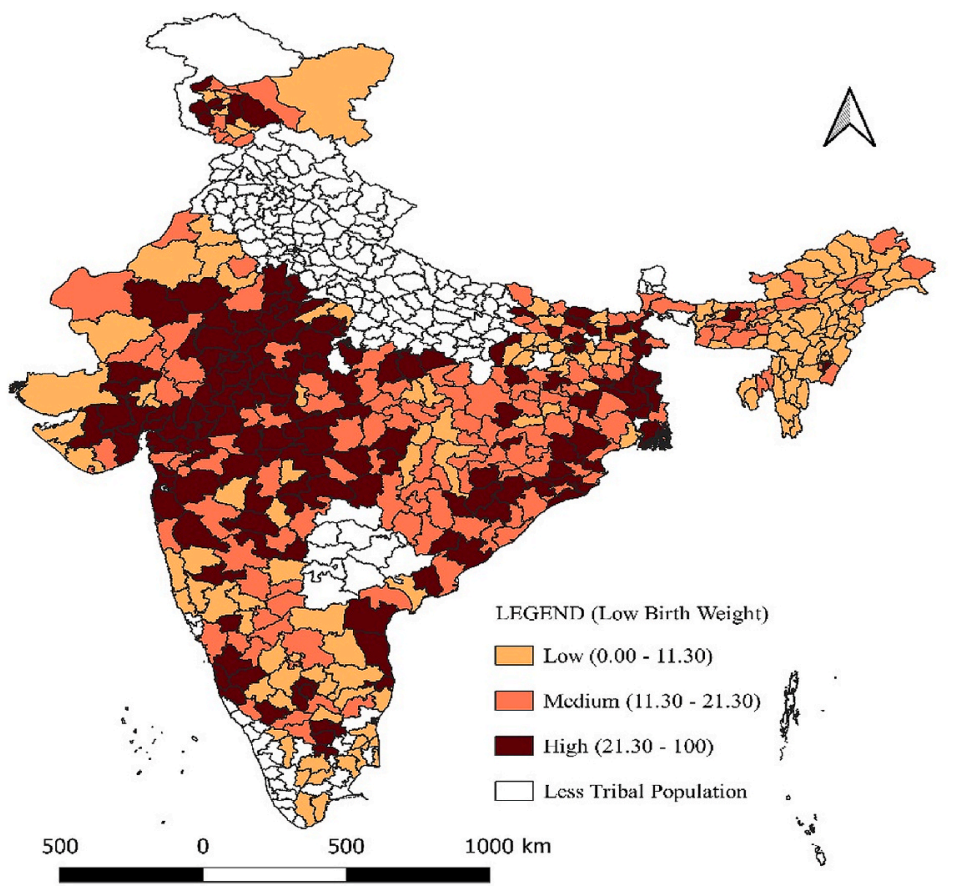

(b)
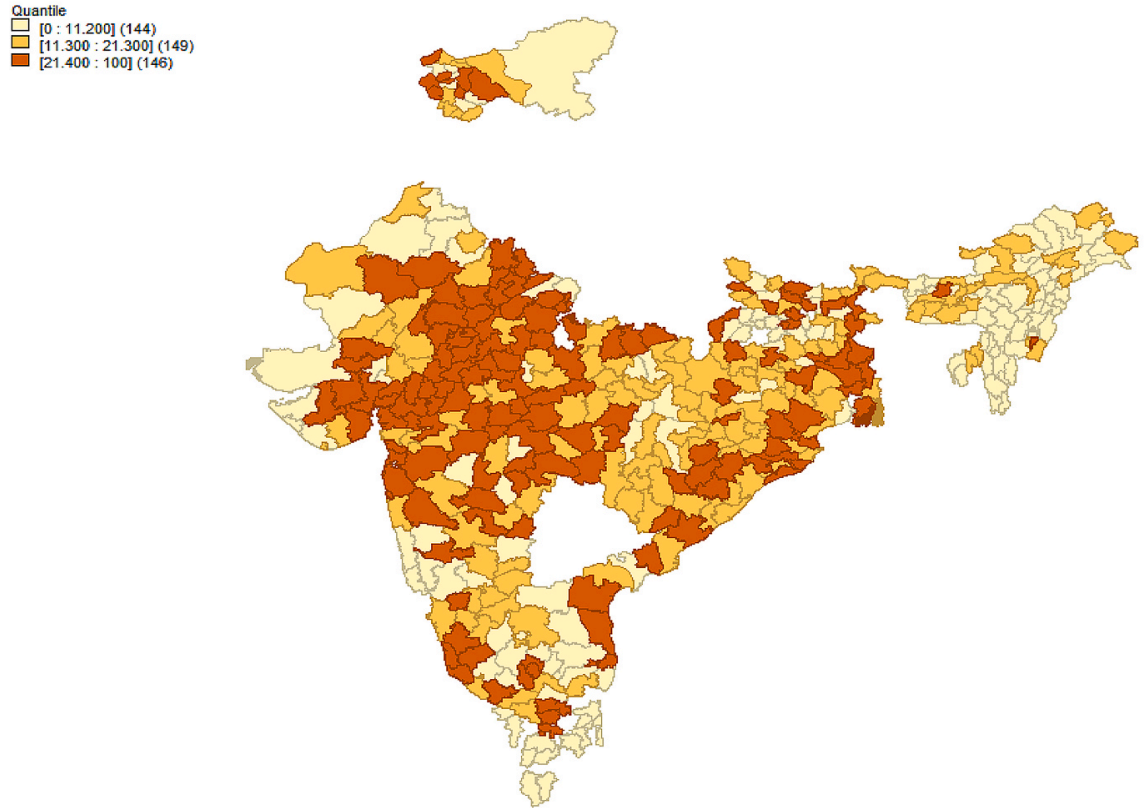

Fig. 3. (a) Prevalence of the LBW ( $<2.5 \mathrm{~kg}$ ) by tribal dominated districts in India. (b) Prevalence of the LBW $(<2.5 \mathrm{~kg})$ by Tribal Dominated Districts in India.

\section{Discussion}

The low birth weight of an infant is an important determinant of a new-born's survival, growth, long term physical and psychological development. $^{1,3,4}$ The developing countries are mainly sharing the major burden of having LBW infants as compared to the developed countries. ${ }^{12,14}$ In this context, developing countries are taking measures to improve the intrauterine growth of the foetus by providing nutritious food and medical services to pregnant women which significantly determine the weight at birth of the newborn. Consistent efforts have been put forward to improve the nutritional level of pregnant women by providing multiple services through public health schemes. The 
(a)

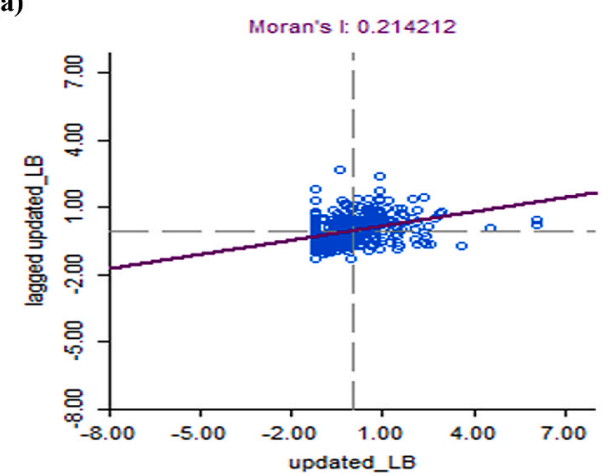

(b)

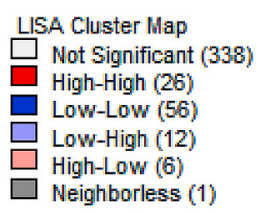

(c)

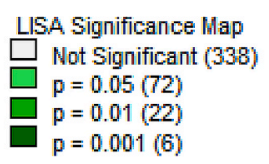

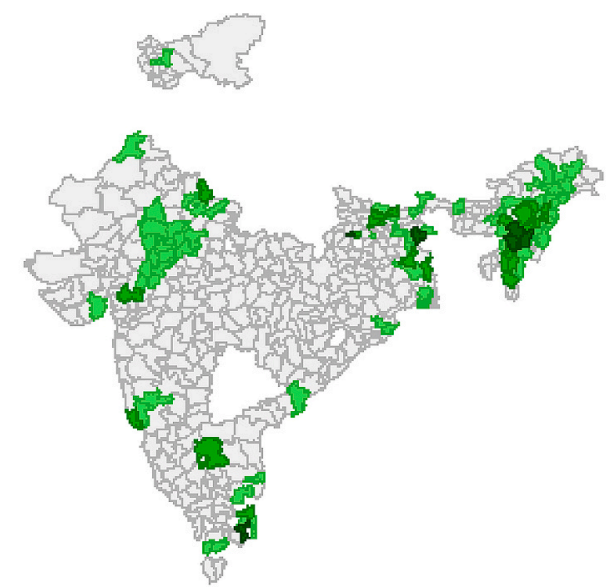

Fig. 4. (a)Univariate Moran's I scattered plot of LBW among Tribal dominated districts in India. (b). Univariate LISA cluster map of LBW among Tribal dominated districts in India. (c). Univariate LISA significance map of LBW among Tribal dominated districts in India.

government of India have various welfare schemes for pregnant women, which look after the nutritional intake of women during pregnancy, early diagnosis of pregnancy complications, financial burden/out-of-pocket expenditure during antenatal care, and delivery. Government of India is also making efforts to provide nutritional intake, ANC and PNC services, financial incentives for mothers and transport facilities for mother and newborn through different policies and programs including Integrated Child Development Services, Pradhan Mantri Matritva Vandana Yojana, Pradhan Mantri Surakshit Matritva Abhiyan, Janani Suraksha Yojana, Janani Shishu Suraksha Karyakaram etc. However, despite the implementation of multiple policies and programs to improve the outcome of delivery, India is still lagging far behind to achieve the target.

Our study findings substantiate the debate with empirical evidence that almost one-fifth of the newborns are born LBW in India. ${ }^{16}$ Particularly, newborns in the socioeconomically disadvantaged communities, such as the scheduled tribe community which shares a higher burden of Low Birth Weight as compared to the newborns of the other community. People residing in the rural areas belonging to lower caste and tribe are more vulnerable to poor health outcomes. ${ }^{14,20}$ Findings reveal that the tribes from the states like Madhya Pradesh,
Maharashtra, Rajasthan, Odisha, Gujarat, Bihar, Karnataka, West Bengal, and Andhra Pradesh have higher LBW newborns as compared to the national average of India. The district-level analysis suggests that altogether, 232 districts have higher LBW newborns than the national average (18.2\%) in India. The districts, including Jhabua, Ashoknagar, Tikamgarh, Mandsaurm, Gwalior of Madhya Pradesh, have higher LBW newborns. Similarly, districts like Buxar, Madhubani, Begusarai, and Saharsa of Bihar; Bharatpour, Gagaur, Jodhpur, and Dhaulpur from Rajasthan have higher LBW infants than the national average. On the other hand, Osmanabad and Hingoli district of Maharashtra; Udupi of Karnataka; Bhadrak of Odisha; Namakkal of Tamil Nadu; Uttar Dinajpur and Murshidabad of West Bengal have more newborns with LBW compare to the national average. Mainly districts from Maharashtra and Madhya Pradesh have proportionality higher LBW because of the low utilization of $\mathrm{MCH}$ services by pregnant women and low socio-economic development in the tribal dominated areas. ${ }^{21}$

At the same time, the socioeconomic characteristics of mothers also determine the weight of newborns. For instance, mothers with low years of age, with no education, who received less than 4 ANC visits and have had multiple pregnancies resulted in having LBW infants as compared with their counterparts. Similarly, the economic status of the 
Table 1

Descriptive statistics for the children birth weight by background characteristic among tribal population in India.

\begin{tabular}{|c|c|c|c|c|}
\hline Background & $(<2.5 \mathrm{Kg})$ & $(\geq 2.5 \mathrm{Kg})$ & Sample Size (N) & Chi-Square \\
\hline \multicolumn{5}{|l|}{ Sex of child } \\
\hline Female & 21.7 & 78.3 & 17,012 & \multirow[t]{2}{*}{.000} \\
\hline Male & 19.4 & 80.6 & 18,017 & \\
\hline \multicolumn{5}{|l|}{ Birth order } \\
\hline First & 22.8 & 77.2 & 13,427 & \multirow[t]{4}{*}{.000} \\
\hline Second & 18.4 & 81.6 & 10,154 & \\
\hline Third & 18.7 & 81.3 & 5837 & \\
\hline Fourth + & 20.8 & 79.2 & 5611 & \\
\hline \multicolumn{5}{|l|}{ Place of residence } \\
\hline Urban & 20.5 & 79.5 & 6260 & \multirow[t]{2}{*}{.000} \\
\hline Rural & 20.5 & 79.5 & 28,769 & \\
\hline \multicolumn{5}{|l|}{ Religion } \\
\hline Hindu & 21.4 & 78.6 & 20,194 & \multirow[t]{3}{*}{.000} \\
\hline Muslim & 22.3 & 77.7 & 1206 & \\
\hline Other & 12.4 & 87.6 & 13,629 & \\
\hline \multicolumn{5}{|l|}{ Mother's age at birth } \\
\hline Less than 18 & 23.0 & 77.0 & 4786 & \multirow[t]{2}{*}{.000} \\
\hline Equal or more than 18 & 20.0 & 80.0 & 30,243 & \\
\hline \multicolumn{5}{|l|}{ Mother's education } \\
\hline No Education & 22.7 & 77.3 & 10,048 & \multirow[t]{4}{*}{.000} \\
\hline Primary & 19.2 & 80.8 & 5702 & \\
\hline Secondary & 20.1 & 79.9 & 17,007 & \\
\hline Higher & 12.7 & 87.3 & 2272 & \\
\hline \multicolumn{5}{|l|}{ ANC visit } \\
\hline No ANC Visit & 22.1 & 77.9 & 3200 & \multirow[t]{3}{*}{.000} \\
\hline Less than 3 & 20.3 & 79.7 & 9084 & \\
\hline Equal or More than 4 & 18.4 & 81.6 & 13,945 & \\
\hline \multicolumn{5}{|l|}{ Wealth Index } \\
\hline Poorest & 22.2 & 77.8 & 11,695 & \multirow[t]{5}{*}{.000} \\
\hline Poorer & 20.4 & 79.6 & 9119 & \\
\hline Middle & 18.4 & 81.6 & 6942 & \\
\hline Richer & 20.9 & 79.1 & 4635 & \\
\hline Richest & 14.1 & 85.9 & 2638 & \\
\hline
\end{tabular}

Sources: National Family Health Survey (NFHS-4, 2015-16).

household has an association with the LBW, i.e., the study found the lowest prevalence among newborn from the richest wealth index and vice-versa. Our findings substantiated with the previous studies and reconfirmed the determinants of LBW in India. ${ }^{22-27}$ The government is fighting at the forefront to limit the prevalence of LBW in India through different policies and programs. However, it needs to be systematically monitored for the rural and tribal areas. The government may target selected districts and states of the country which are having a higher prevalence of LBW newborns, particularly for the states of Madhya Pradesh, Maharashtra, Rajasthan, Odisha, Gujarat, Bihar, Karnataka, West Bengal, and Andhra Pradesh.

\section{Conclusions and recommendations}

Women education and antenatal care are vital determinants that need to be addressed to reduce prevalence of LBW in India. Continue implementation of multifaceted health promotion interventions are needed to address these factors effectively. The women education, nutritional status and ANC services need to be addressed to reduce prevalence of LBW among the tribal in states and districts of India. ANC services are key services to monitor the pregnant women. Priority to the regular monthly weighting and growth monitoring for children may be adopted as the effective public health strategy to reduce LBW among the tribal dominated districts in India.

\section{Authors contribution}

Pradeep S Salve and Nutan Kumari: Conceptualization, Methodology and Manuscript writing. Kisan Algur: Data analysis and mapping. Praveen Chokhandre: Review and edited manuscript. All authors read and approved the final manuscript.
Table 2

Logistic regression analysis of the children birth weight by background characteristic of tribal population.

\begin{tabular}{|c|c|c|c|c|}
\hline \multirow[t]{2}{*}{ Background } & \multirow[t]{2}{*}{ Sig. } & \multirow[t]{2}{*}{$\mathrm{EXP}(\mathrm{B})$} & \multicolumn{2}{|c|}{ 95\% C.I. for $\operatorname{EXP(B)}$} \\
\hline & & & Lower & Upper \\
\hline \multicolumn{5}{|l|}{ Sex of child } \\
\hline \multicolumn{5}{|l|}{ Female ${ }^{\circledast}$} \\
\hline Male & 0.000 & 0.88 & 0.82 & 0.94 \\
\hline \multicolumn{5}{|l|}{ Birth order } \\
\hline \multicolumn{5}{|l|}{ First $^{\oplus}$} \\
\hline Second & 0.000 & 0.79 & 0.72 & 0.86 \\
\hline Third & 0.000 & 0.73 & 0.66 & 0.81 \\
\hline Fourth + & 0.000 & 0.75 & 0.67 & 0.84 \\
\hline \multicolumn{5}{|l|}{ Place of residence } \\
\hline \multicolumn{5}{|l|}{ Urban $^{\circledast}$} \\
\hline Rural & 0.94 & 0.293 & 0.84 & 1.05 \\
\hline \multicolumn{5}{|l|}{ Religion } \\
\hline \multicolumn{5}{|l|}{ Hindu® } \\
\hline Muslim & 0.296 & 1.10 & 0.92 & 1.32 \\
\hline Other & 0.000 & 0.41 & 0.37 & 0.44 \\
\hline \multicolumn{5}{|l|}{ Mother's age at birth } \\
\hline \multicolumn{5}{|l|}{ Less than $18^{\circledR}$} \\
\hline Equal and more than 18 & 0.049 & 0.90 & 0.82 & 1.00 \\
\hline \multicolumn{5}{|l|}{ Mother's education } \\
\hline \multicolumn{5}{|l|}{ No Education ${ }^{\circledast}$} \\
\hline Primary & 0.013 & 0.87 & 0.78 & 0.97 \\
\hline Secondary & 0.000 & 0.76 & 0.69 & 0.84 \\
\hline Higher & 0.000 & 0.65 & 0.53 & 0.79 \\
\hline \multicolumn{5}{|l|}{ ANC visit } \\
\hline \multicolumn{5}{|l|}{ No ANC Visit ๑ } \\
\hline Less than 3 & 0.047 & 0.89 & 0.80 & 1.00 \\
\hline Equal and more than 4 & 0.000 & 0.80 & 0.72 & 0.89 \\
\hline \multicolumn{5}{|l|}{ Wealth Index } \\
\hline \multicolumn{5}{|l|}{ Poorest $^{\oplus}$} \\
\hline Poorer & 0.020 & 0.90 & 0.82 & 0.98 \\
\hline Middle & 0.022 & 0.88 & 0.78 & 0.98 \\
\hline Richer & 0.005 & 0.81 & 0.70 & 0.94 \\
\hline Richest & 0.000 & 0.67 & 0.54 & 0.81 \\
\hline
\end{tabular}

Sources: National Family Health Survey (NFHS-4, 2015-16); ® Reference Category.

\section{Availability of data and materials}

The data used for the study is obtained from the National Family Health Survey- 2015-2016. And the NFHS data supporting the findings of this study is available in the public domain for download (https:// dhsprogram.com/data/available-datasets.cfm). No separate ethics statement and consent for publication was required for this study as the NFHS followed ethical clearance guidelines and norms.

\section{Funding}

No funding for this study.

\section{Conflicts of interest}

Authors declare 'no conflict of interest'.

\section{Acknowledgements}

Not applicable.

\section{References}

1. World Health Organization, \&United Nations International Children's Emergency Fund. Low Birth Weight: Country, Regional and Global Estimates. WHO; 2004.

2. Singh G, Chouhan R, Sidhu K. Maternal factors for low birth weight infants. Med $J$ Armed Forces India. 2009;65(1):10-12.

3. World Health Organization. Towards the Development of a Strategy for Promoting Optimal Fetal Growth. Geneva: WHO; 2004.

4. World Health Organization. Guidelines on Optimal Feeding of Low Birth-Weight Infants 
in Low-And Middle-Income Countries. WHO; 2011.

5. Blencowe H, Krasevec J, De Onis M, et al, National, regional, and worldwide estimates of low birthweight in 2015, with trends from 2000: a systematic analysis. The Lancet Global Health. 2019;7(7):849-860.

6. United Nations International Children's Emergency Fund. State of the World's Children: Celebrating 20 Years of the Convention on the Rights of the Child. UNICEF; 2009.

7. Narwade RG, More UB. Comparative study of birth weight in newborns in tribal and non-tribal area in Marathwada region of Maharashtra, India. Indian J Obstet Gynecol Res. 2018;5(4):496-499.

8. Niswade A, Zodpey SP, Ughade S, et al. Neonatal morbidity and mortality in tribal and rural communities in central India. Indian J Community Med: official publication of Indian Association of Preventive \& Social Medicine. 2011;36(2):150

9. Rajashree K, Prashanth HL, Revathy R. Study on the factors associated with low birth weight among newborns delivered in a tertiary-care hospital, Shimoga, Karnataka. Int J Med Sci Publ Health. 2015;4(9):1287-1291.

10. Shashikantha $S$, Sheethal M. Prevalence of low birth weight and its associated factors: a community based cross sectional study in a rural area of Rohtak, Haryana, India. International Journal of Community Medicine and Public Health 2017;3(6):1544-1546

11. Wilcox AJ. On the importance-and the unimportance-of birthweight. Int $J$ Epidemiol. 2001;30(6):1233-1241.

12. He Z, Bishwajit G, Yaya S, et al. Prevalence of low birth weight and its association with maternal body weight status in selected countries in Africa: a cross-sectional study. BMJ open. 2018;8(8):020410.

13. Moosan H, Stanley A, Prabhakaran AO, et al. Comparison of health-care utilization pattern and its correlates among the tribal and nontribal population of Kerala. Indian $J$ Community Med: official publication of Indian Association of Preventive \& Social Medicine. 2019;44(Suppl 1):S57

14. Dey U, Bisai S. The prevalence of under-nutrition among the tribal children in India: a systematic review. Anthropol Rev. 2019;82(2):203-217.

15. Nair NS, Rao RP, Chandrashekar S, et al. Socio-demographic and maternal determinants of low birth weight: a multivariate approach. Indian $J$ Pediatr 2000;67(1):9-14.

16. IIPS and ICF. National Family Health Survey (NFHS-4), 2015-16. 2017; 2017 Mumbai, India.

17. Office of Registrar General \& Census Commissioner India. CensusInfo. Ministry of Home Affairs, Government of India; 2011.

18. Metgud CS, Naik VA, Mallapur MD. Factors affecting birth weight of a newborn-a community-based study in rural Karnataka, India. PloS One. 2012;7(7):40040.

19. Malhotra N, Upadhyay RP, Bhilwar M, et al. The role of maternal diet and iron-folic acid supplements in influencing birth weight: evidence from India's National Family Health Survey. J Trop Pediatr. 2014;60(6):454-460.

20. Kshatriya GK, Ghosh A. Undernutrition among the tribal children in India: tribes of Coastal, Himalayan and Desert ecology. Anthropol Anzeiger. 2008:355-363.

21. Narwade RG, More UB. Comparative study of birth weight in newborns in tribal and non-tribal area in Marathwada region of Maharashtra, India. Indian J Obstet Gynecol Res. 2018;5(4):496-499. https://doi.org/10.18231/2394-2754.2018.0112.

22. Kapoor SK, Kumar G, Pandav CS, et al. Incidence of low birth weight in rural ballabgarh, Haryana. Indian Pediatr. 2001;38:271-275.

23. Biswas R, Dasgupta A, Sinha RN, et al. An epidemiological study of low birth weight newborns in the district of puruliya, West Bengal. Indian J Publ Health 2008;52(2):65-71.

24. Ghate MM, Pratinidhi AB, Gupte AM. Effects of maternal nutritional status on birth weight of the baby. J Obstet Gynaecol India. 2001;51(1):38-41.

25. Joshi HS, Subba SH, Dabral SB, et al. Risk factors associated with low birth weight in newborns. Indian J Community Med. 2005;30(4):142-143.

26. Nair NS, Rao RSP, Chandrashekar S, et al. Socio-demographic and maternal determinants of low birth weight: a multivariate approach. Indian J Pediatr. 2000;67(1):9-14

27. Banerjee A, Singh AK, Chaurasia H. An exploratory spatial analysis of low birth weight and its determinants in India. Clin Epidemiol Global Health. 2020;8(3):702-711 In press. 